Case Report

\title{
Ankle arthrodesis with cannulated screw: Case series
}

\author{
Andre Triadi Desnantyo ${ }^{1^{*}}$, Muhammad Zaim Chilmi ${ }^{2}$, Hizbillah Yazid $^{3}$ \\ 1,2) Teaching Staff of the Department of Orthopedics and Traumatology, Faculty of Medicine, Airlangga \\ University - Dr. Soetomo Academic Medical Center Hospital Surabaya \\ 3) Orthopedic and Traumatology Resident, Faculty of Medicine, Airlangga University Dr. Soetomo Academic \\ Medical Center Hospital Surabaya
}

\section{ART I C LE IN FO \\ Submitted : April 2019 \\ Accepted : September 2019 \\ Published : January 2020}

Keywords:

Ankle arthrodesis, cannulated screw, ankle joint fusion

*Correspondence:

tyo.dharma@gmail.com

\begin{abstract}
Ankle osteoarthritis patients are young and lack of available long last treatment. Ankle arthrodesis remains the gold standard and is the procedure of choice for younger patients who are heavy laborers. These case series evaluate and report five patients undergone ankle arthrodesis at RSUD Dr. Soetomo Surabaya on 2012-2016. The data were collected from patient files, radiographs, and a recent physical examination. The outcome has been assessed with SF-36 score and clinical scoring system Ankle-Hind foot American Foot and Ankle Society. Three male patients and two female patients underwent ankle arthrodesis with cannulated screw, caused by neglected severe ankle dislocation. One patient had open dislocation. Based on SF-36 scoring, the five patients had average score 76,7 with highest and lowest score were 95,9 and 56,7. Based on clinical score ankle-hind foot American Ankle and Foot Society, the average score was 68(51-88). The scoring result includes general health, physic, emotional, and social. And clinical scoring anklehind foot American Foot and Ankle Society evaluation includes pain, function, and alignment. It shows that there was patient that gains an almost perfect result. Patient with the lowest score also had knee osteoarthritis contralateral from the operated ankle. Early weight bearing on ankle arthrodesis with cannulated screw was the major factor caused unsatisfactory result of this patient. Ankle arthrodesis with cannulated screw has satisfactory result eventhough remain complain on one patient. Nevertheless, ankle arthrodesis with cannulated screw still has an important role in the treatment of choice on ankle reconstruction.
\end{abstract}




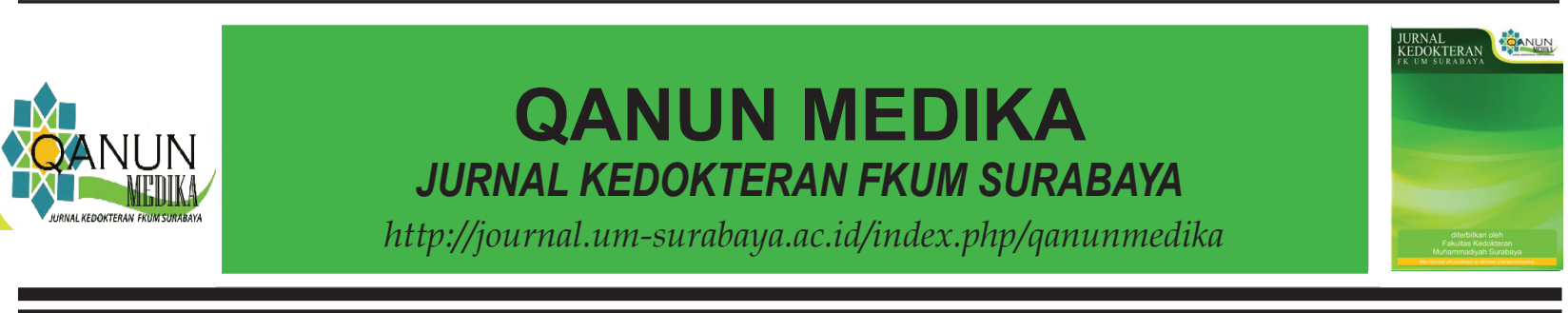

\section{INTRODUCTION}

Ankle osteoarthritis is a severe problem with an increasing prevalence that handicapped patients life. About 50,000 new cases are reported annually in the United States (Saltzman et al., 2009). From the cadaveric study, the prevalence of grade 3 and 4 ankle arthritis was found by $18 \%$ (Weatherall et al, 2013). Trauma is the most common cause of ankle osteoarthritis, up to $70 \%$ of cases. The most common causes are ankle rotational fractures $(37 \%)$, recurrent ankle instability (14.6\%), and history of sprains with persistent pain $(13.7 \%)$. Primary osteoarthritis is only found in 7.2\% of cases (Saltzman et al., 2009).

Ankle osteoarthritis is unique compared to the hip and knee joints. Patients have a younger average age and therapy that can last for a long time has not been established yet. In the late stages, ankle osteoarthritis can cause joint deformity, disability, and reduced income. This can have an impact on the patient's quality of life.

In the case of post-traumatic ankle osteoarthritis, the choice of non-operative treatment includes NSAIDs, stick use, orthotics, orthosis, and injections including corticosteroids, hyaluronic acid, and plateletrich plasma. While the choice of operative treatment includes joint surface reconstruction with allografts, arthroscopic debridement and osteophytic resection, joint distraction arthroplasty, supramaleolar osteotomy, total joint replacement, and fusion of ankle joints. Ankle joint fusion is still the gold standard for the management of ankle osteoarthritis, especially at a young age who are still working. Joint replacement is better used in older patients with not too many activities (Weatherall et al., 2013).

In the current era, where the new interest is more towards total ankle joint replacement, joint fusion still has an important role and is widely used as an alternative reconstruction (Tenenbaum et al., 2014). A fusion of the ankle joint, which was initially used as surgical therapy in cases of ankle joint tuberculosis, continues to play a role in patients with functional disorders of the ankle joint by various reasons (Abidi et al., 2000).

Despite concerns about loss of movement from the ankle and subtalar joint, this combination of fusion of the two joints is still indicated in cases of severe bone loss, severe deformity, and advanced arthritis. Tibiotalocalcaneal joint fusion is still considered clinically successful in the treatment of advanced arthritis and/or severe deformity in the tibiotalar and subtalar joints. Although there are several surgical techniques for the fusion of tibiotalocalcaneal joints, the aim of all of these is to relieve pain and stabilize biomechanical plantigrade positions of the ankle and soles of the feet (Alfahd et al., 2005).

The fusion of cannulated screw joints has high union numbers, minimal complications, better comfort for patients, and more simple surgical techniques. This can also reduce the need for additional surgery and extensive post-operative rehabilitation (Tenenbaum et al., 2014). These thoughts encourage us to evaluate patients undergoing cannulated screw fusion surgery at Dr. Soetomo Hospital Surabaya.

\section{CASE REPORT}

This case series evaluated 5 patients who had undergone ankle arthrodesis procedure at Dr. Seotomo Hospital Surabaya in 2012-2016. Data was collected through medical records, physical examinations, and radiography. The results were measured by the SF-36 scoring and the Ankle-Hind Foot American Foot and Ankle Society clinical scoring system. This study included three male and two female patients who had undergone cannulated screw ankle arthrodesis due to severe ankle dislocation. One patient with an open dislocation. 


\section{Patient 1}

A 61-year-old male patient with pain and bleeding in the right ankle after an accident. The patient was riding a motorbike and hit by a motorcycle from the opposite direction, 5 hours before arriving at the emergency unit. The patient is treated as fracture and dislocation of the right ankle joint with open fractures of the medial malleolus, lateral malleolus, and calcaneus. The patient also suffered a total rupture of the right extensor halucis longus and the right extensor digitorum longus.

Patients underwent emergency surgery for the debridement and application of external fixation at the emergency department of RSUD Dr. Soetomo on May 18, 2014. Patients underwent a post-operative follow-up examination on 1-day postoperative (Figure 2.A-C). Two weeks after, the patient underwent a follow-up examination dated June 3, 2014. (Figure 2.D) On three months postoperative, the patient underwent a follow-up examination dated August 8, 2014. (Figure 2.E) On examination, a plain photo of the ankle was found a union in the malleolus and fibula. External removal of trans ankle fixation was carried out on November 18, 2014. At six months post-externally fixation of trans-ankle, a plain photo of the ankle had been found with union of the malleolus and fibula. (Figure 2.F) On December 4th 2014, right ankle arthrodesis was performed. On 7 months postoperative examination, a patient's plain ankle photo had not shown any union in the ankle joint. (Figure 2.G) At present patients still complain of pain in the ankle, especially when walking and decreasing with rest. The patient cannot return to work as before the incident.

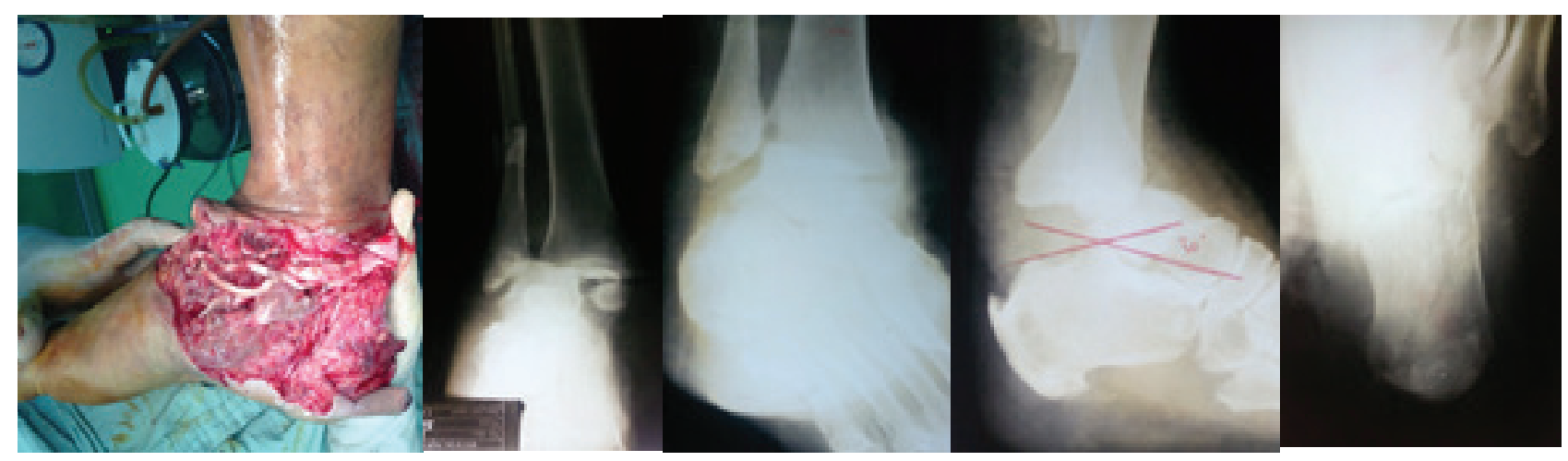

Figure 1. Pre-operative clinical and radiological 


\section{QANUN MEDIKA Vol 4 No 1 JANUARY 2020}
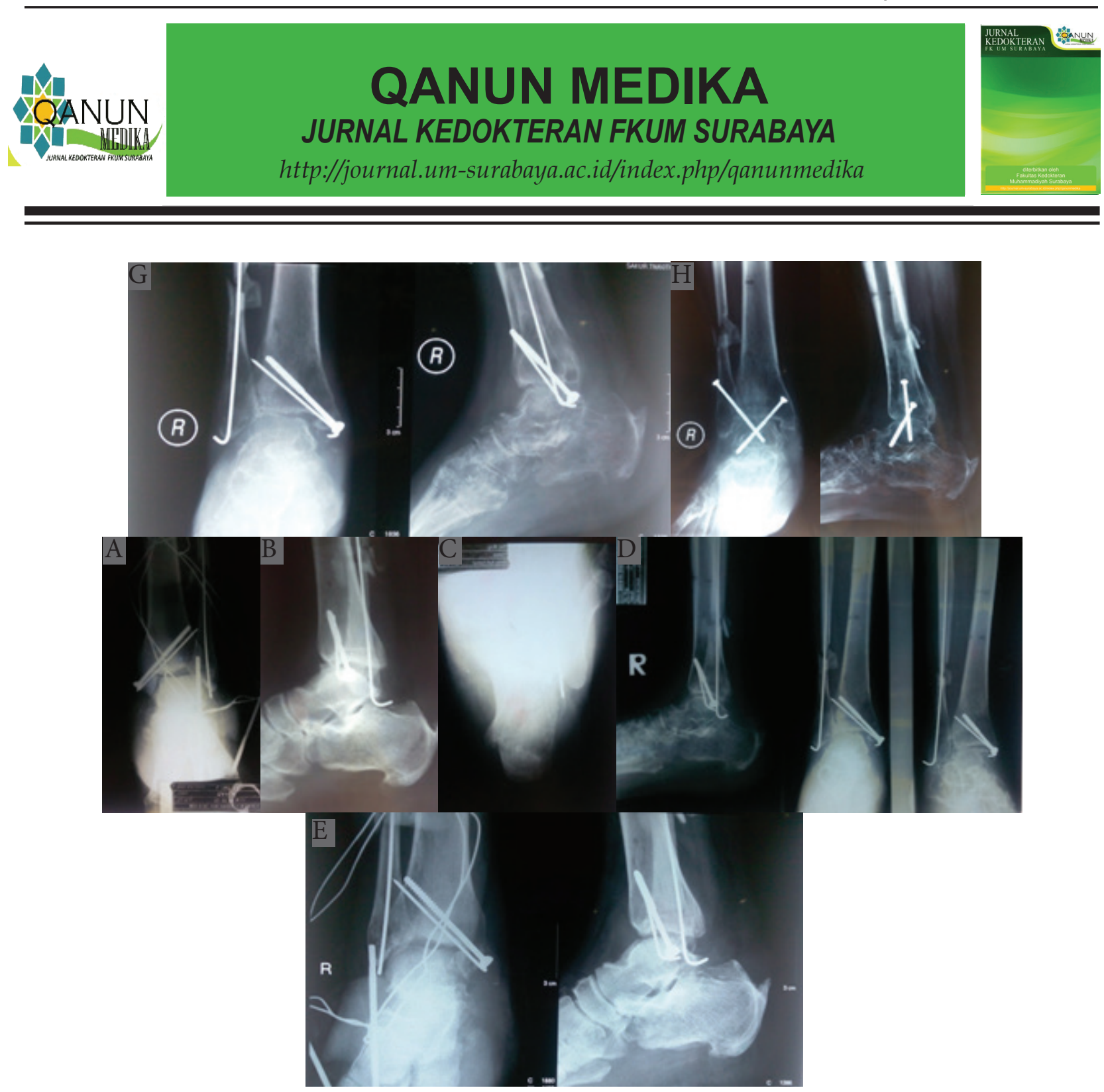

Figure 2. (A-C) post-emergency operative radiological (D) 2 weeks post-external fixation trans-ankle dextra radiological evaluation (E) 3 months post-external fixation trans-ankle dextra radiological evaluation (F) 6 months post-external fixation trans-ankle dextra radiological evaluation $(\mathrm{G})$ radiological evaluation of post-operative of ankle joint fusion with cannulated screw

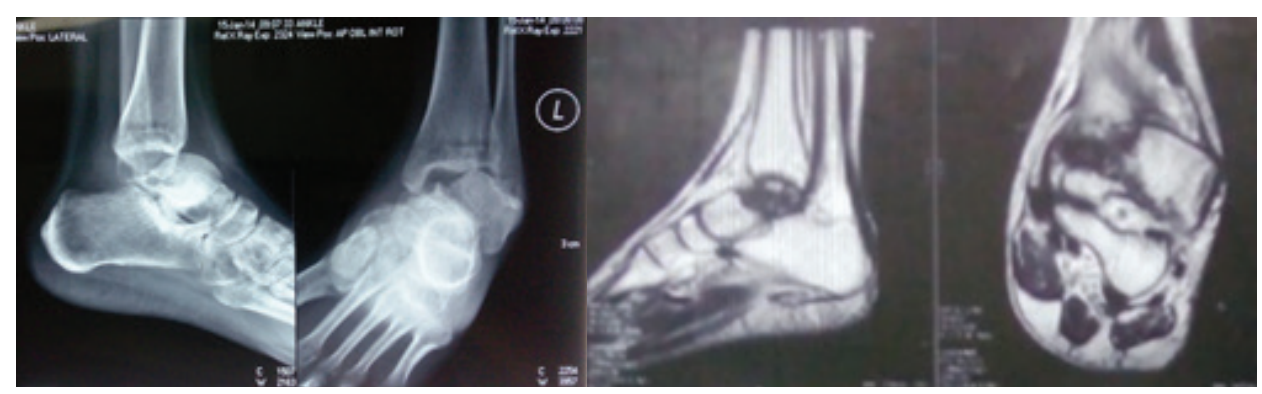

Figure 3. X Ray and MRI of left ankle before operation 


\section{QANUN MEDIKA \\ JURNAL KEDOKTERAN FKUM SURABAYA \\ http://journal.um-surabaya.ac.id/index.php/qanunmedika}

\section{Patient 2}

A 26-year-old female patient complained of limping and pain in the left ankle since falling from a height of 3 meters at two months before visiting the Orthopedic Clinic of RSUD Dr. Soetomo Surabaya. The patient went to alternative medicine immediately after falling. The patient's first visit to the polyclinic was on January 15, 2014 and diagnosed with a neglected dislocation of the left ankle joint.

The patient underwent surgery of the talotibial and subtalar joints fusion by two cannulated screws and a bone graft on February 20, 2014 (Figure 4.A-C). The follow-up examination of 6 weeks postoperative on April 1, 2014 showed the union at ankle joint. (Figure 4. D-E). At ten weeks postoperative on 28 April 2014, the removal of the left-hand lateral ankle screw was carried out. The union of ankle joint was continuously found at three months (Figure 4.F-G), seven months (Figure 4.H-I), and 9 months (Figure 4.J-K) follow-up after removal of lateral ankle screw. A month after latest follow-up, the residual implant was removed on December 23, 2014. The ankle union was found from plain photo examination (Figure 4.L-N). During the last evaluation of 2 years postoperatively the patient did not feel any complaints of pain and obstacles in daily activities.

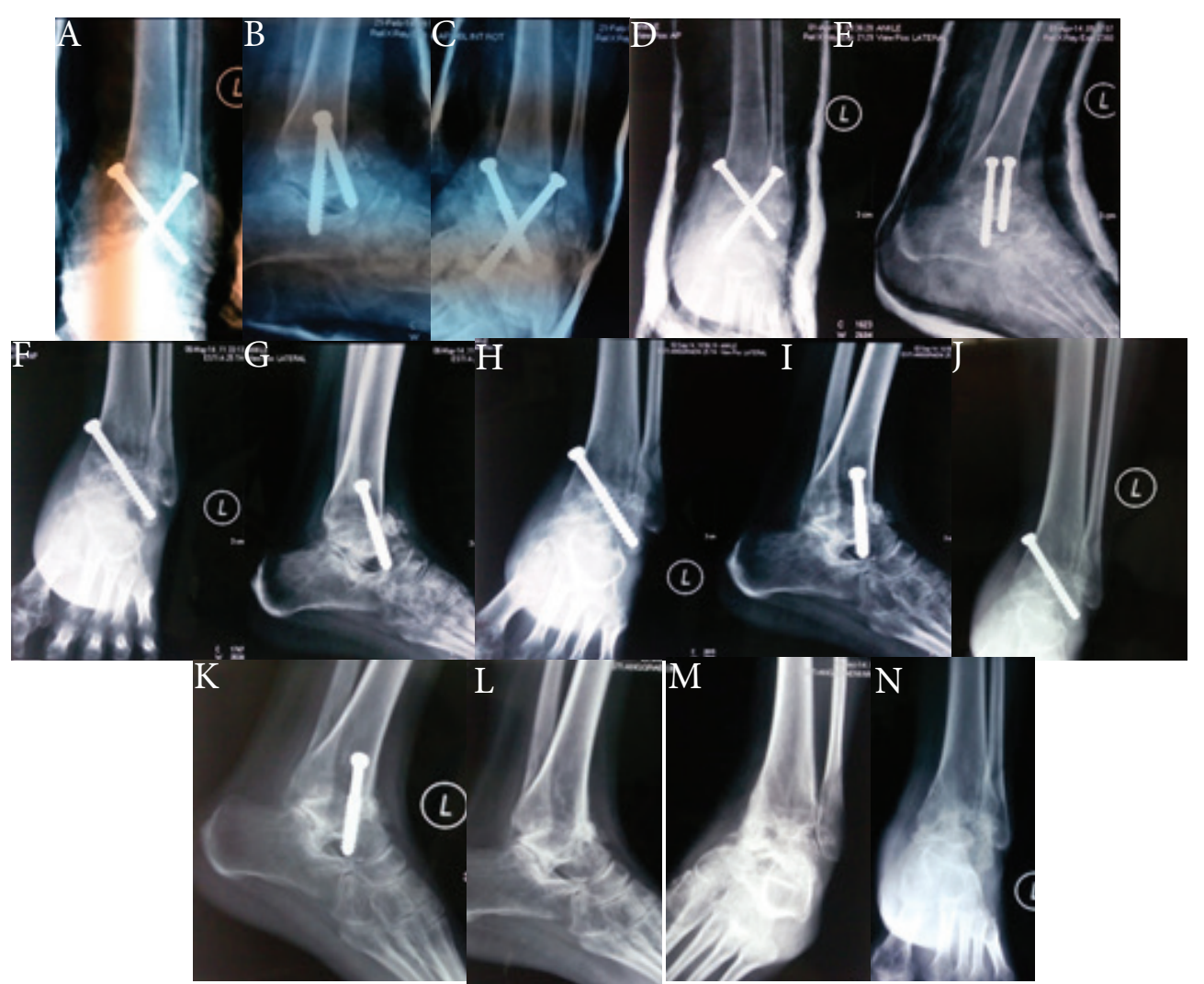

Figure 4. (A-C) Radiological evaluation after talotibial and subtalar surgery with 2 cannulated screws and bone graft. (DE) Radiological evaluation of left ankle 6 weeks after left ankle arthrodesis (FG) Radiological evaluation of left ankle 3 months after left ankle arthrodesis (HI) Radiological evaluation of left ankle 7 months after left ankle arthrodesis (JK) Radiological evaluation of left ankle 9 months after ankle Cystic arthrodesis (LN) Post implant release evaluation by evaluation of talotibial and subtalar joint fusion 


\section{QANUN MEDIKA Vol 4 No 1 JANUARY 2020}
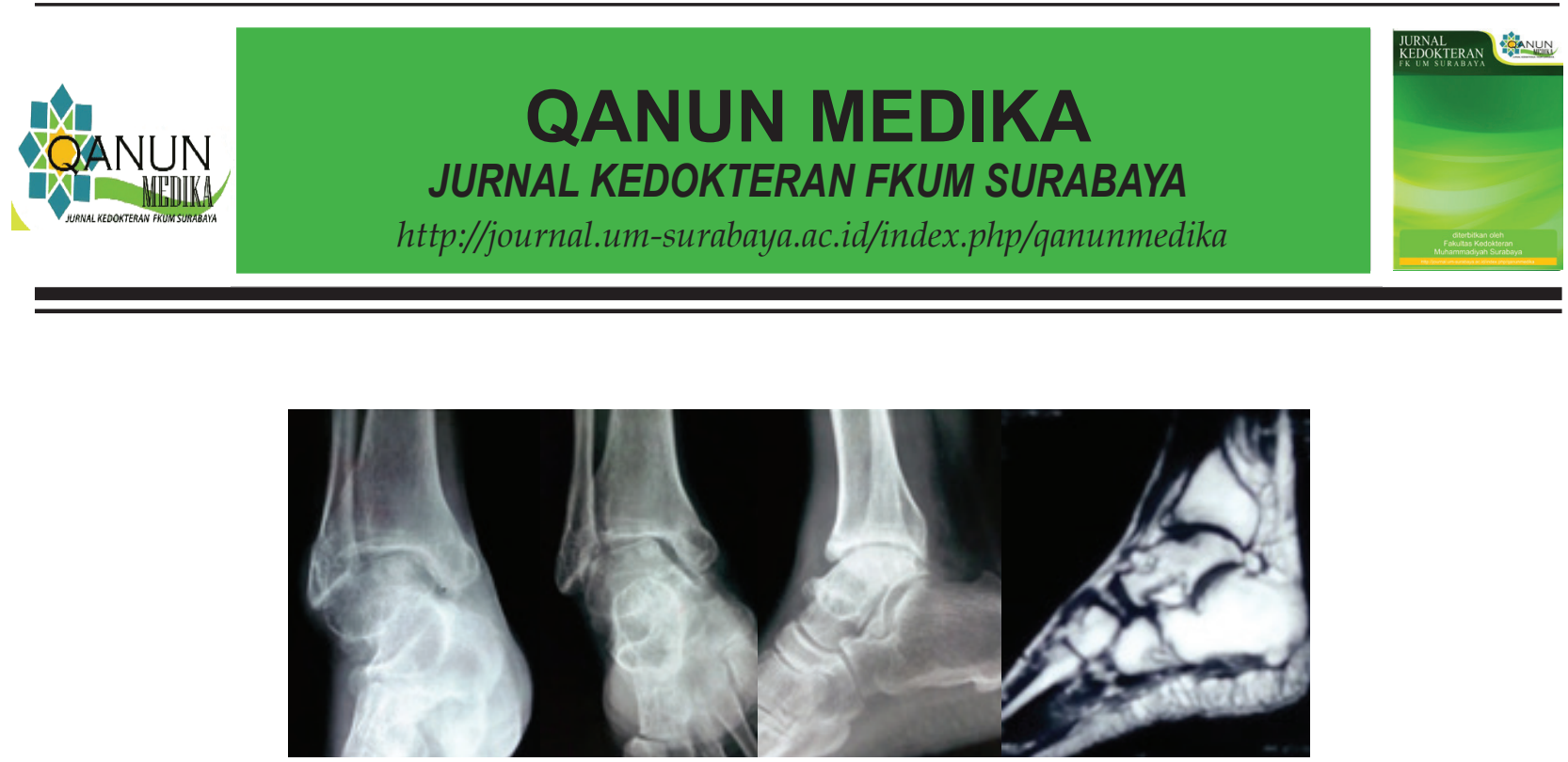

Figure 5. Overview of Plain Photographs and MRI of the right ankle shows subluxation and posttraumatic osteorthritis in patient 3

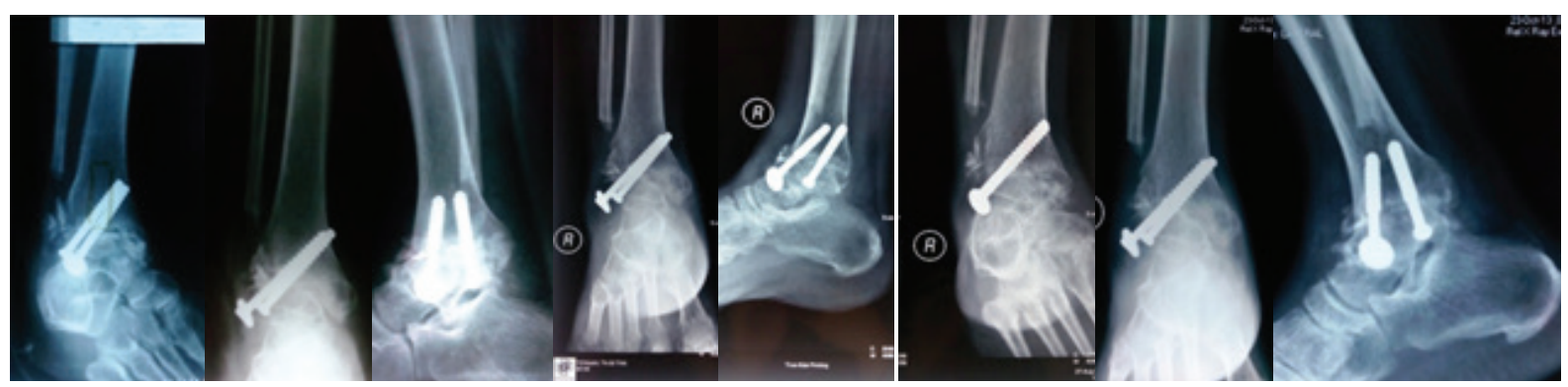

Figure 6. (A-C) Immediate radiological evaluation after fusion surgery (D-F) Radiological evaluation of extra ankle 2 months after extra ankle arthrodesis (G-H) Radiological evaluation of extra ankle four months after ankle arthrodesis dextra (A-C)

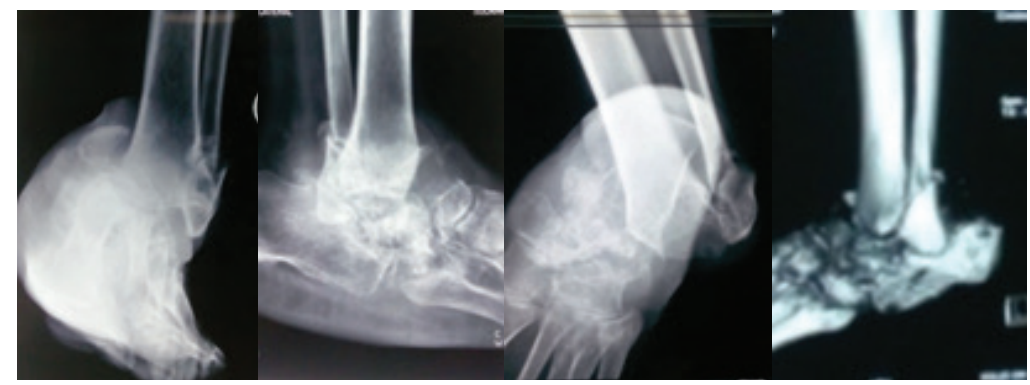

Figure 7. Plain X-Rays and CT-Scan of left ankle of patient 4 (pre-operation)

\section{Patient 3}

The 52-year-old male patient complained of right ankle pain since sprained while playing soccer two months before visiting the Orthopedic Clinic of Dr. Soetomo Hospital Surabaya. The pain was aggravated while walking and supporting body weight and decreased with rest. The patient also complained of swelling that diminished after 6 weeks after injury. The patient was diagnosed with neglected subluxation of the right ankle joint with post-traumatic osteoarthritis.
The patient underwent a talo-tibial joint fusion surgery by 2 parallel cannulated screws with distal fibular excision and the addition of bone graft on June 10, 2013 (Figure 6.A-C). Union was started seen on ankle radiological plain examination two months after surgery (Figure 6.D-F). Union was also obtained in ankle radiological plain examination of 4 months evaluation, on 23 October 2013 (Figure 6.G$\mathrm{H})$. During 3 years postoperative, patients do not complain of pain or obstacles in carrying out work activities. 


\section{QANUN MEDIKA \\ JURNAL KEDOKTERAN FKUM SURABAYA \\ http://journal.um-surabaya.ac.id/index.php/qanunmedika}

\section{Patient 4}

A 50-year-old male patient had left ankle pain since falling while pushing a cart eight years before going to the Orthopedic Clinic of Dr. Soetomo Hospital Surabaya. The patient had a history of going to alternative medicine and have only been able to walk with a stick since then. Patients were diagnosed with left ankle neglected dislocation with osteoarthritis of the joint.

The patient had been treated at the Clinic since February 2014 and underwent plantar fusion surgery with two crossing cannulated screws and the bone graft on June 23, 2014 (Figure 8.A-C). On one month after surgery on July 22
2014, the left ankle radiological examination showed no union yet (Figure 8.D-E). The union started to occur from ankle radiological followup at two months (Figure 8.F-H), three months (Figure 8.I-K), and eight months (Figure 8.L-M) post-operative. The union continued found on 14-months evaluation of the ankle joint (Figure 8.O-P). On the evaluation three years after surgery, the patient complained of left ankle pain with high impact activity while decreased by rest. The patient has not been returned to work as before the accident.
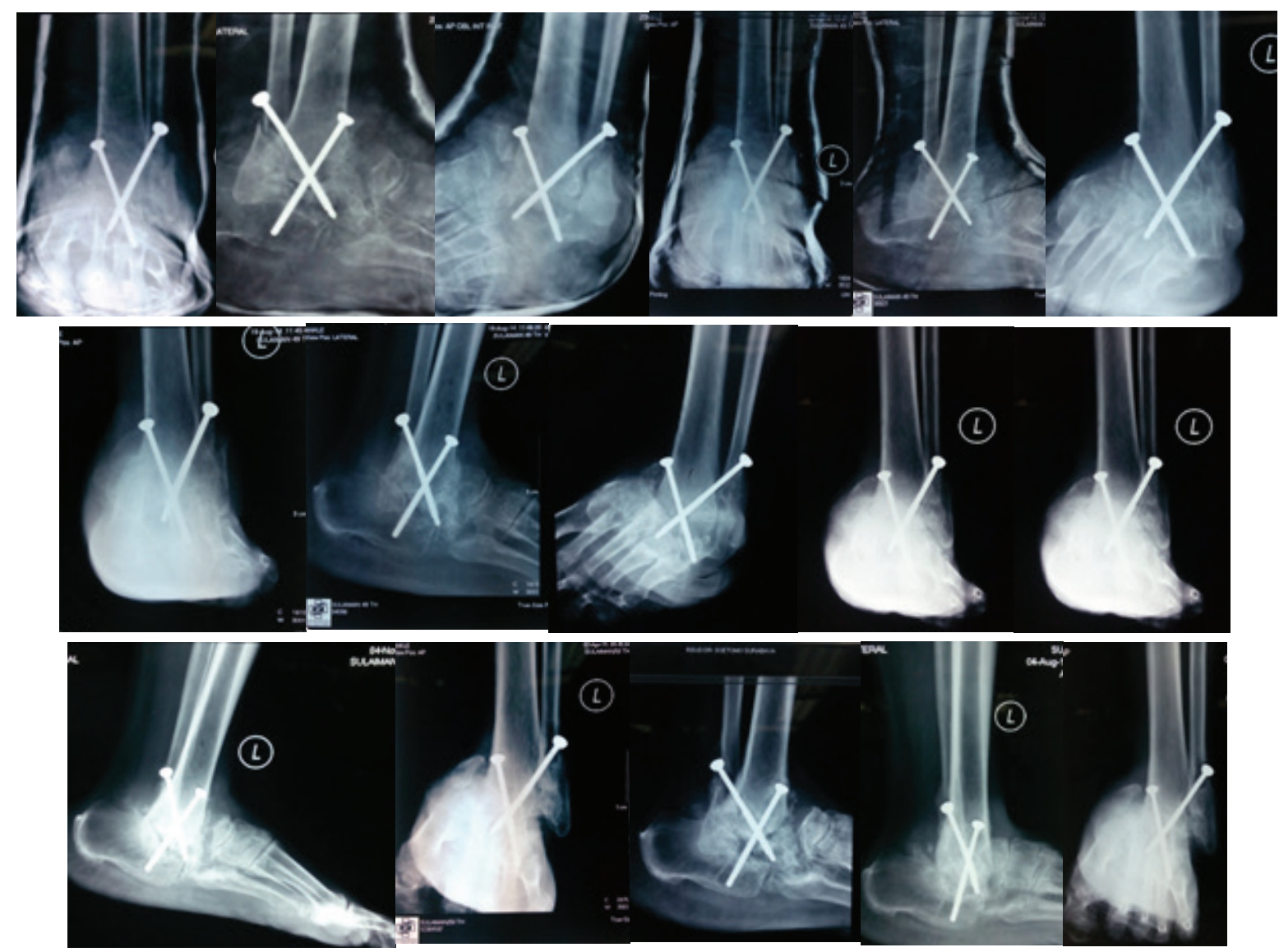

Figure 8. (A,B,C) Immediate radiological evaluation after fusion surgery $(D, E)$ Radiological evaluation of left ankle 1 month after left ankle arthrodesis (F,G,H) Radiological evaluation of left ankle 2 months after left ankle arthrodesis (I,J,K) Radiological evaluation of left ankle 3 months after left ankle arthrodesis (L,M) Radiological evaluation of left ankle 8 months after left ankle arthrodesis and (O,P) 14 months postoperatively 


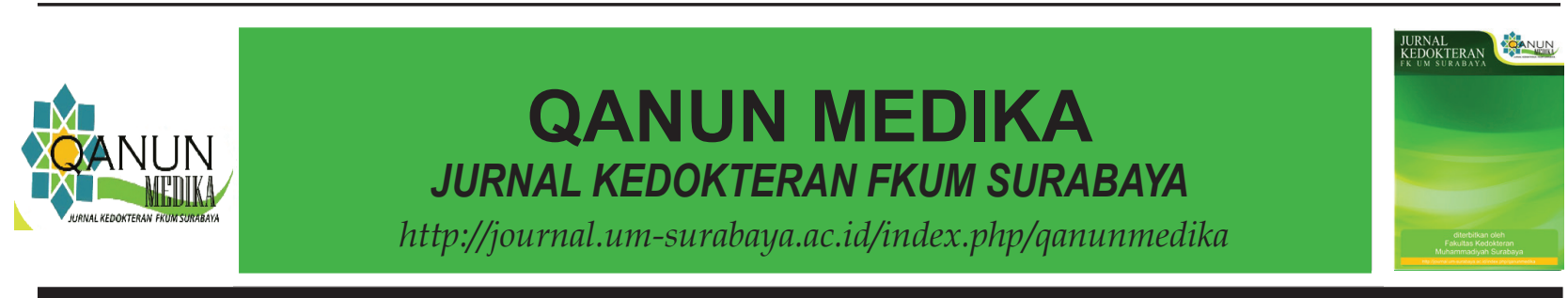

\section{Patient 5}

A 44-year-old female patient complained of pain and swelling of the left ankle after a motorcycle accident that crashed to the left side, four months before visiting the Orthopedic Clinic of Dr. Soetomo Surabaya. The patient went to alternative medicine right after the event. The patient complained that the pain was aggravated by walking and followed by swelling after standing for a long duration. Patients were diagnosed with neglected ankle joint dislocation talus fracture. Preoperative radiological data documentation cannot be obtained. The patient underwent a cannulated screw and stapler fusion surgery also augmentation with bone graft. Follow up radiological examination was obtained one day after surgery on November 22, 2011 (Figure 9.AC). Radiological re-examination at one month after surgery on December 20, 2011 still did not show union of the joint yet (Figure 9.D-E). The union of the joint could be evaluated on the six months (Figure 9.F-G) and ten months (Figure 9.H-I) follow-up radiological examination. The union of the joint also showed on the latest four years follow-up evaluation (Figure 9.H-I). Clinically, the patient sometimes complaining of pain when walking away and decreasing with rest. However, patient still can work as an administrative staff until the four years after surgery.

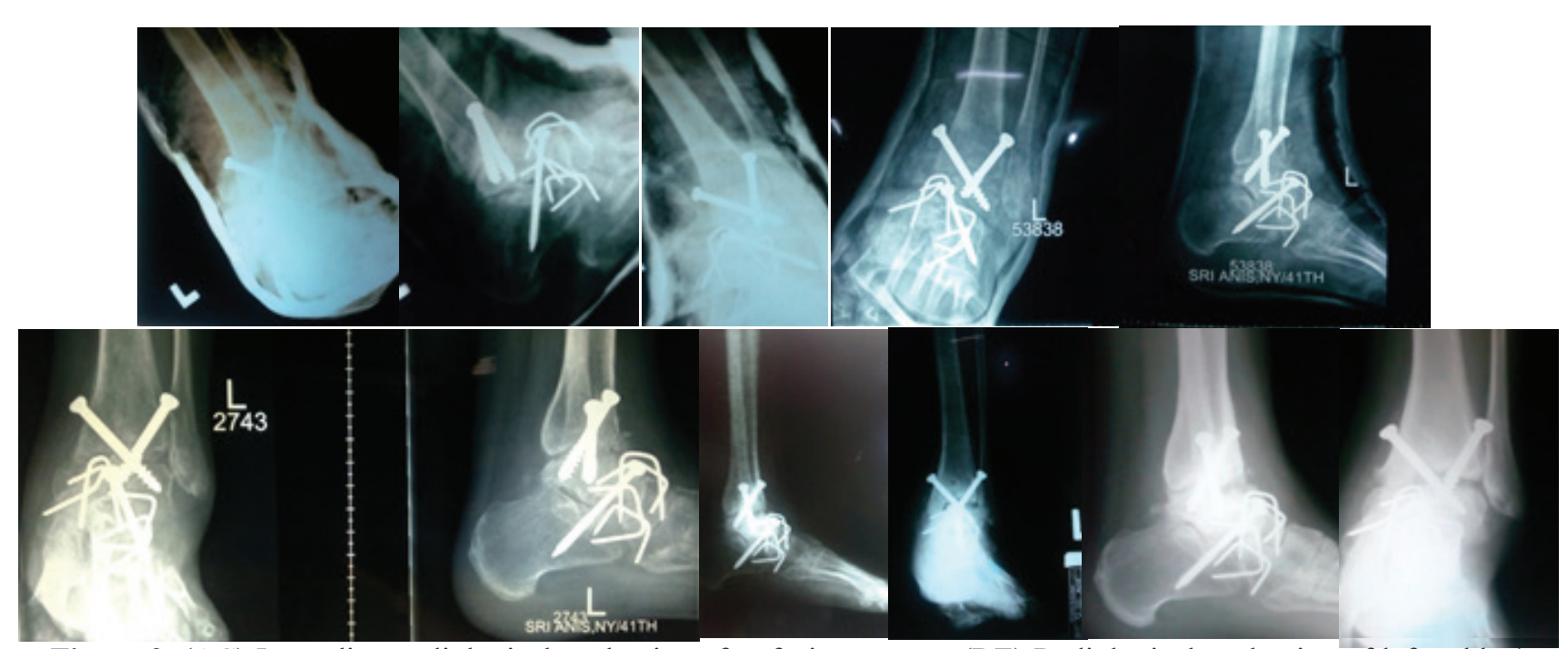

Figure 9. (AC) Immediate radiological evaluation after fusion surgery (DE) Radiological evaluation of left ankle 1 month after left ankle arthrodesis (FH) Radiological evaluation of left ankle 2 months after left ankle arthrodesis (IK) Radiological evaluation of left ankle 3 months after left ankle arthrodesis (LM ) Radiological evaluation of left ankle 8 months after left ankle arthrodesis and (OP) 14 months postoperatively 


\section{DISCUSSION}

Based on the results of the SF-36 scoring covering general, physical, emotional, and social health aspects, the average score of the five patients is 76.7 with the highest score reaching 95.9 and the lowest score of 56.7. This data shows that there are patients who have achieved almost perfect result from cannulated screw ankle fusion procedures. But there is still patient who still suffer complaints after undergoing this procedure.

In a study conducted by Hendricson et al, bilateral ankle arthrodesis resulted from satisfactory results in patients through SF36 assessment. Ankle arthrodesis was a good treatment of choice forcases of hindfootarthritis with high satisfaction rates in postoperative intermediate reporting (Hendricson et al., 2016). Concomitant conditions in the surrounding joints, especially in the subtalar joint, will have a large impact on clinical outcomes and have a significant relationship to the SF-36 quality of life assessment results in patients undergoing arthrodesis, whereas radiological results are not too important for quality of life assessment. (Fuchs et al., 2003).

The condition of patient 1 and patient 4 had a low SF-36 value, most likely because in patient 1 had a long follow-up history where the initial condition of the patient with open fracture was very severe whereas in patient 4 there was a right knee osteoarthritis disease causing the low quality of life assessment results. However, most patients provide high satisfaction and arthrodesis is still the treatment of choice in ankle osteoarthritis.

From the clinical scoring of the anklehindfoot American Orthopedic Foot and Ankle Society, the patient's average score was 68 from a maximum of 100 . The highest score reached 88 , and the lowest score was 51 . In this scoring, the aspects assessed included pain, function, and alignment. Thus, it can be concluded that there are patients who have relatively satisfactory clinical scores from the cannulated screw ankle joint fusion procedure. But there are still patients with lower scores which means that patients still suffer from complaints after undergoing this procedure.

Schuh et al. reported that there was no significant difference in the clinical outcome of the AOFAS score in the treatment of ankle osteoarthritis with arthrodesis and total ankle arthroplasty. So the arthrodesis procedure is chosen because the technique is more simple and doesn't take much time (Schuh et al, 2011).

Herrera-Perezetal.reported the useofcannulated screw in ankle arthrodesis giving an increased AOFAS clinical score. Compared to the Compression Staples for Subtalar Arthrodesis Fixation technique, the use of cannulated screw technique has better functional results (Herrera-Perez, et al., 2015). The combined application of the anterior contoured plate and cross screw fixation provides better stability than the technique of crossed screw fixation alone which provides a higher probability of union occurrence. In the study of Kakarala et al. provides a better picture of clinical outcomes in combination techniques (Kakarala et al., 2006).

From the clinical aspect, patients who had the lowest score were patients 4. In this patient, knee osteoarthritis was obtained from the contralateral side from the ankle who underwent surgery. This becomes comorbid because reducing the patient's adherence to not loading weight sufficiently at the postoperative rehabilitation due to contralateral knee pain. So that the earlier loading of weight on the fusion of the ankle joint with cannulated screw is the main factor causing the unsatisfactory results obtained in this patient.

The advantage of our cannulated screw technique is that provides a shorter operating duration and provides easier fixation and reduction in the hindfoot area. 


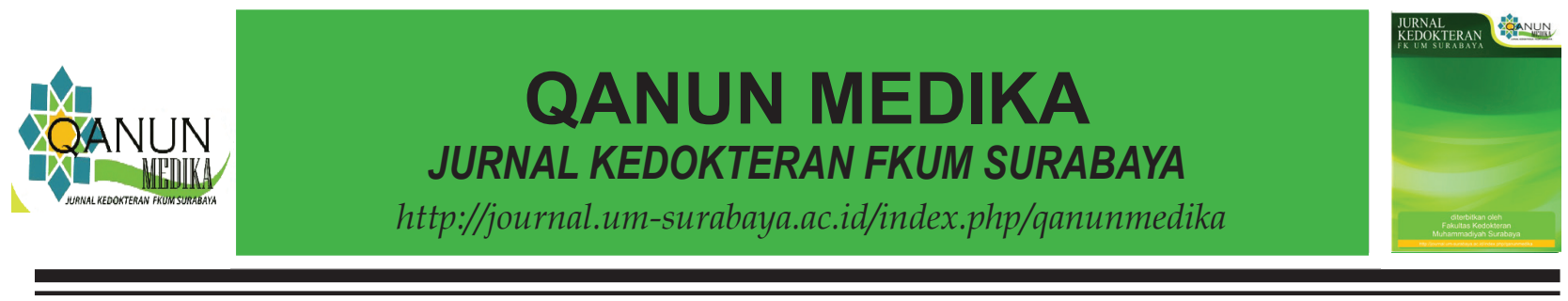

Table 1. SF - 36 Scoring on patient 1,2,3,4, dan 5

\begin{tabular}{|c|c|c|c|c|c|c|c|}
\hline \multirow[t]{2}{*}{ No. } & & \multicolumn{5}{|c|}{ Patient } & \multirow[t]{2}{*}{ Average } \\
\hline & & 1 & 2 & 3 & 4 & 5 & \\
\hline \multicolumn{8}{|c|}{ GENERAL CONDITION } \\
\hline 1. & $\begin{array}{l}\text { General health status Current health } \\
\text { level compared to } 1 \text { year ago }\end{array}$ & 80 & 100 & 100 & 80 & 80 & 88 \\
\hline 2. & $\begin{array}{l}\text { General health status Current health } \\
\text { level compared to } 1 \text { year ago }\end{array}$ & 80 & 100 & 100 & 100 & 80 & 92 \\
\hline
\end{tabular}

\section{ACTIVITY BARRIER}

3. Heavy activities (such as running, $\begin{array}{lllllll}0 & 50 & 50 & 0 & 0 & 20\end{array}$ lifting heavy weights, and strenuous exercise)

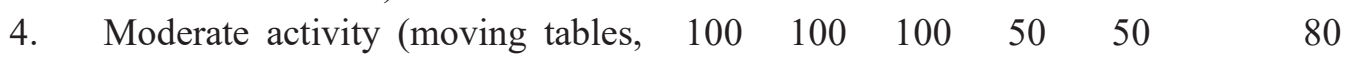
pushing vacuum cleaners, bowling, playing golf)

$\begin{array}{lllllll}\text { 5. Lift or carry groceries } & 100 & 100 & 100 & 50 & 100 & 90\end{array}$

$\begin{array}{lllllll}\text { 6. Climb up some stairs } & 50 & 100 & 50 & 50 & 50 & 60\end{array}$

$\begin{array}{lllllll}\text { 7. Climb up a ladder } & 100 & 100 & 100 & 100 & 100 & 100\end{array}$

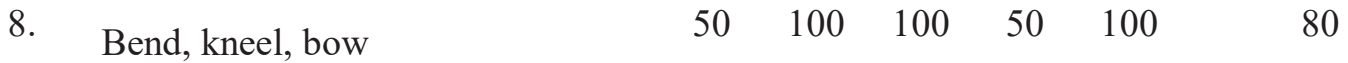

9. Runs more than 1 mile $\quad \begin{array}{llllll}0 & 50 & 50 & 0 & 0 & 100\end{array}$

$\begin{array}{lllllll}\text { 10. Walk a few blocks } & 50 & 100 & 100 & 50 & 50 & 70\end{array}$

$\begin{array}{lllllll}\text { 11. Walk one block } & 100 & 100 & 100 & 50 & 100 & 90\end{array}$

12. Bathe and dress alone $\quad \begin{array}{lllllll}100 & 100 & 100 & 100 & 100 & 100\end{array}$

$\begin{array}{llllll}65 & 90 & 85 & 50 & 65 & 71\end{array}$

PHYSICAL HEALTH PROBLEM

13. Reduced time spent on work or $\quad \begin{array}{lllllll}0 & 0 & 100 & 0 & 100 & 40\end{array}$ other activities

$\begin{array}{lllllll}\text { 14. Reach less than expected } & 0 & 100 & 100 & 0 & 100 & 60\end{array}$

$\begin{array}{llllllll}\text { 15. Barriers to work or do other } & 0 & 100 & 100 & 0 & 100 & 60\end{array}$ activities

16. Having trouble running work or $\begin{array}{llllll}0 & 100 & 100 & 0 & 0 & 40\end{array}$ other activities 
EMOTIONAL HEALTH PROBLEM

17. Reduced time spent on work or

$\begin{array}{lllll}0 & 100 & 100 & 0 & 100\end{array}$

60 other activities

18. Reach less than expected

19. Do not do work or other activities

$\begin{array}{llllll}0 & 100 & 100 & 0 & 100 & 60\end{array}$

as well as usual

$\begin{array}{llllll}0 & 0 & 100 & 0 & 100 & 40\end{array}$

$\begin{array}{llllll}0 & 66,7 & 100 & 0 & 100 & 53,3\end{array}$

\section{SOCIAL ACTIVITY}

20. Emotional problems affect social $\quad \begin{array}{lllllll}100 & 100 & 100 & 100 & 100 & 100\end{array}$ activities in family, friendship, neighbors, or groups?

$\begin{array}{llllll}100 & 100 & 100 & 100 & 100 & 100\end{array}$

\section{PAIN}

21. How severe physical pain is $\quad \begin{array}{lllllll}60 & 80 & 100 & 60 & 60 & 72\end{array}$ experienced in these past 4 weeks?

22. During the past 4 weeks, how $\begin{array}{lllll}60 & 100 & 100 & 50 & 100\end{array}$ much pain affected work?

$\begin{array}{llllll}60 & 90 & 100 & 55 & 80 & 77\end{array}$

\section{EMOTION AND ENERGY}

23. Are you excited?

$\begin{array}{cccccc}60 & 100 & 100 & 80 & 80 & 84 \\ 80 & 80 & 80 & 80 & 80 & 80 \\ 60 & 100 & 80 & 80 & 60 & 76\end{array}$

24. Are you anxious?
$25 . \quad$ Do you feel very bad and nobody

26. Do you feel calm and peaceful?

$\begin{array}{llllll}80 & 100 & 80 & 80 & 80 & 84\end{array}$

27. Do you have a lot of energy?

28. Do you feel low and worse?

29. Do you feel too hard-working?

$\begin{array}{llllll}60 & 80 & 80 & 60 & 80 & 72\end{array}$

$\begin{array}{llllll}60 & 100 & 80 & 80 & 80 & 80\end{array}$

$\begin{array}{llllll}80 & 100 & 80 & 80 & 80 & 84\end{array}$

30. Are you a happy person?

$\begin{array}{llllll}60 & 100 & 100 & 80 & 80 & 84\end{array}$

31. Do you feel tired?

$\begin{array}{llllll}60 & 100 & 80 & 80 & 80 & 80\end{array}$

$\begin{array}{llllll}66,7 & 95,6 & 84,4 & 77,8 & 77,8 & 80,5\end{array}$




\section{QANUN MEDIKA \\ JURNAL KEDOKTERAN FKUM SURABAYA \\ http://journal.um-surabaya.ac.id/index.php/qanunmedika}

\section{SOCIAL ACTIVITY}

32.

In the past 4 weeks, how much

$\begin{array}{lllll}75 & 100 & 100 & 75 & 100\end{array}$

90

time for your social activities is interrupted by physical or emotional problems?

$\begin{array}{llllll}75 & 100 & 100 & 75 & 100 & 90\end{array}$

\section{GENERAL HEALTH CONDITION}

33. I feel sick more easily than others

$\begin{array}{llllll}100 & 75 & 75 & 50 & 75 & 65\end{array}$

34. I am as healthy as anyone I know

$\begin{array}{llllll}100 & 75 & 100 & 50 & 75 & 70\end{array}$

35. I thought my health was getting

$\begin{array}{lllll}100 & 75 & 100 & 75 & 75\end{array}$
worse

36. My health is at a good level

\section{TOTAL}

$\begin{array}{cccccc}50 & 100 & 100 & 75 & 75 & 80 \\ 82,5 & 81,3 & 93,8 & 62,5 & 75 & 72,5 \\ \mathbf{5 8 , 8} & \mathbf{8 8 , 7} & \mathbf{9 5 , 9} & \mathbf{5 6 , 7} & \mathbf{8 3 , 6} & \mathbf{7 6 , 7}\end{array}$

Table 2. Clinical scoring of ankle-hindfoot American Orthopedic Foot and Ankle Society patients 1, 2, 3, 4 and 5

\begin{tabular}{|c|c|c|c|c|c|c|c|c|}
\hline \multirow[t]{2}{*}{ CRITERIA } & \multirow[t]{2}{*}{ GRADE } & & \multicolumn{5}{|c|}{ Patient } & \multirow{2}{*}{$\begin{array}{c}\text { AVER } \\
\text { AGE }\end{array}$} \\
\hline & & & 1 & 2 & 3 & 4 & 5 & \\
\hline \multirow[t]{2}{*}{ Pain } & & & 30 & 4 & 4 & 3 & 30 & 34 \\
\hline & & & & 0 & 0 & 0 & & \\
\hline No pain & 40 & 40 & 30 & 4 & 4 & 3 & 30 & 34 \\
\hline Light, Occasionally arises & 30 & & & 0 & 0 & 0 & & \\
\hline Medium, every day & 20 & & & & & & & \\
\hline Heavy, almost always arises & 0 & & & & & & & \\
\hline \multirow[t]{2}{*}{ Function } & & 50 & 22 & 3 & 3 & 2 & 30 & 29 \\
\hline & & & & 4 & 8 & 1 & & \\
\hline \multirow{2}{*}{ Activity barriers, assistance needs } & & & 7 & 1 & 1 & 7 & 10 & 8,8 \\
\hline & & & & 0 & 0 & & & \\
\hline There are no obstacles, no need for help & 10 & & & & & & & \\
\hline There are no obstacles to daily & 7 & & & & & & & \\
\hline \multicolumn{9}{|l|}{ activities, there are obstacles to certain } \\
\hline activities, no need for help & & & & & & & & \\
\hline $\begin{array}{l}\text { There are obstacles to daily activities, } \\
\text { need to use a stick }\end{array}$ & 4 & & & & & & & \\
\hline
\end{tabular}




\section{QANUN MEDIKA}

There are severe obstacles to daily

0 activities; use walkers, crutches,

wheelchairs, braces

Surface in walking

Do not experience obstacles on any surface

Some obstacles on the uphill, stairs Heavy barriers on uphill and ladder roads

\section{Walking Style Abnormalities}

Nothing

Light

Clearly seen

Sagittal movements (flexion and extension)

Normal or slightly blocked $\left(30^{\circ}\right.$ or

more)

Medium resistance $\left(15^{\circ}\right.$ to $\left.29^{\circ}\right)$

Obvious obstacles (less than $15^{\circ}$ )

\section{Hindfoot movement}

Normal or slight resistance ( $75 \%$ to

$100 \%$ normal)

Moderate barriers (25\% to $74 \%$ of

normal)

Clear barriers (less than 25\% normal) 0

Ankle-Hindfoot stability

Stable

Very unstable

Alignment

Good, plantigrade legs, ankle and hindgoot alignmet both good

Moderate, foot plantigrade, seen multiple degrees of ankle-hindfoot malalignment, without complaints $\mathrm{Bad}$, feet not plantigrade, severe malalignment, complaints

TOTAL $\begin{array}{llllll}3 & 5 & 5 & 3 & 5 & 4,2\end{array}$

5

3

0

$\begin{array}{llllll}4 & 8 & 8 & 4 & 4 & 5,6\end{array}$

8

4

0

8

4

0

$\begin{array}{llllll}0 & 3 & 3 & 3 & 3 & 2,4\end{array}$

6

3

0

$\begin{array}{llllll}8 & 8 & 8 & 0 & 8 & 6,4\end{array}$

8

0

10

10

$\begin{array}{llllll}10 & 1 & 1 & 0 & 5 & 7 \\ & 0 & 0 & & & \\ 10 & 1 & 1 & 0 & 5 & 7 \\ & 0 & 0 & & & \end{array}$

5

0

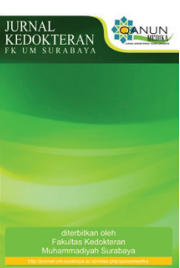




\section{QANUN MEDIKA \\ JURNAL KEDOKTERAN FKUM SURABAYA \\ http://journal.um-surabaya.ac.id/index.php/qanunmedika}

While the weakness of this technique is that the stability of the ankle is less compared to the plate and screw technique. In full-threaded screw, there is a possibility of fewer fixation shifts that can affect the union of the ankle joint. However, in this case report there was no correlation between union and clinical outcomes or quality of life of the patients.

\section{CONCLUSION}

From this case series, the cannulated screw ankle fusion procedure had satisfactory results despite leaving complaints in one patient sample. That failure was due to patient compliance on early weight-bearing. However, fusion of the ankle joint with cannulated screw still has a role in the treatment choice for ankle joint reconstruction. Further research is still needed regarding the results of the ankle fusion procedure using cannulated screw with a larger amount of samples and a longer observation period. It is also necessary to know the factors that can determine the prognosis of cannulated screw ankle fusion procedure outcome.

\section{REFERENCES}

Abidi, NA. Gruen, GS. Conti, SF. (2000) Ankle Arthrodesis: Indications and Techniques. J Am Acad Orthop Surg; 8: 200209

Alfahd, U. Roth, SE. Stephen, D. Whyne, CM. (2005) Biomechanical Comparison of Intramedullary Nail and Blade Plate Fixation for Tibiocalcaneal Arthrodesis. J Orthop Trauma; 19(10): 703-8

Alvarez, RG. Barbour, TM. Perkins, TD. (1994) Tibiocalcaneal Arthrodesis for Nonbraceable Neuropathic Ankle Deformity. Foot Ankle Int; 15: 354-59

Buck, P. Morrey, BF. Chao, EY. (1987) The Optimum Position of Arthrodesis of The Ankle: A Gait Study of The Knee and Ankle. J Bone Joint Surg Am; 69:105262
Cobb, TK. Gabrielsen, TA. Campbell, DC 2nd. Wallrichs, SL. Ilstrup, DM. (1994) Cigarette Smoking and Nonunion After Ankle Arthrodesis. Foot Ankle Int; 15: 64-67

Domsic, RT. Saltzman, CL. (1998) Ankle Osteoarthritis Scale. Foot Ankle Int; 19: 466-71

Fuchs,S. Sandmann, C. Swakara, A. Chylarecki, C. (2003) Quality of Life 20 years after arthrodesis of the ankle. A study of adjacent joints. J Bone Joint Surg Br; 85(7):994-8

Garcia, S. Camacho, P. Segur, JM. Fernandez De Retana, P. Combalia, A. (2001) Stress Fracture of The Tibia After Ankle Arthrodesis: a Review of Three Cases. Foot and Ankle Surgery Vol 7: Issue 3, 175-180

Gruen, GS. Mears, DC. (1991) Arthrodesis of The Ankle and Subtalar Joints. Clin Orthop; 268: 15-20

Hendericson, A. Kamrad,I. Rosengren, B. Carlsson, A. (2016) Bilateral Arthrodesis of the Ankle Joint: Self Reported Outcomes in 35 Patients From the Swedish Ankle Registry. The Journal of Foot and Ankle Surgery 55: 1195-1198

Herrera-Perez,M. Andarica-Banuelos,C. et al. (2015) Comparison of Cannulated Screws Versus Compression Staples for Subtalar Arthrodesis Fixation. Foot and Ankle International Vil 36(2) 203-210.

Kakarala,G. Rajan, D. Comparative Study of Ankle Arthrodesis Using Cross Screw Fixation Versus Anterior Contoured Plate plus Cross Screw Fixation. Acta Orhtop 2006,72, 716-721.

Malarkey, RF. Binski, JC. (1991) Ankle Arthrodesis with the Calandruccio Frame and Bimalleolar Onlay Grafting. Clin Orthop; 268: 44-48

Mann, RA. (1982) Biomechanical Approach to The Treatment of Foot Problems. Foot Ankle; 2: 205-12

Mann, RA. Rongstad, KM. (1998) Arthrodesis of The Ankle: A Clinical Analysis. Foot Ankle Int; 19: 3-9

Myerson, MS. Quill, G. (1991) Ankle Arthrodesis: A Comparison of An Arthroscopic and An Open Method of Treatment. Clin 
Orthop; 268: 84-95

Paremain, GD. Miller, SD. Myerson, MS. (1996) Ankle Arthrodesis: Result After The Miniarthrotomy Technique. Foot Ankle Int; $17: 247-52$

Pinzur, MS. Kelikian, A. (1997) Charcot Ankle Fusion with A Retrograde Locked Intramedullary Nail. Foot Ankle Int; 18: 699704

Schuh, R. Hoffstaeter, J. Krismer, M. et al. (2012) Total Ankle Arthroplasy Versus Ankle Arhtrodesis, Comparison of Sports, Recreational Activities and Functional Outcome. International Orthopaedics (SCIOT) 36:1207-1214.

Tenenbaum, S. Coleman, SC. Brodsky, JW. (2014) Improvement in Gait Following Combined Ankle and Subtalar Arthrodesis. J Bone Joint Surg Am; 96:1863-9

Thevendran, G. Shah, K. Pinney, SJ. Younger, ASE. (2017) Perceived Risk Factors for Nonunion Following Foot and Ankle Arthrodesis. Journal of Orthopaedic Surgery; 25(1): 1-6
Thodarson, DB. Markolf, K. Cracchiolo, A 3rd. (1994) External Fixation in Arthrodesis of The Ankle: A Biomechanical Study Comparing A Unilateral Frame with A Modified Transfixtion Frame. $J$ Bone Joint Surg Am; 76: 1541-44

Troullier, H. Hansel, L. Schaff, P. Rosemeyer, B. Refior, HJ. (2002) Long-Term Result After Ankle Arthrodesis: Clinical, Radiological, Gait Analytical Aspects. Foot and Ankle International; Vol: 23 Issue: 12; 1081-1090

Saltzman, CL. Mann, RA. Ahrens, JE. (2009) Prospective Controlled Trial of STAR Total Ankle Replacement versus Ankle Fusion: Initial Resuls. Foot Ankle Int; 30(7): 576-96

Weatherall, JM. Mroczek, K. McLaurin, T. Ding, B. Tejwani, N. (2013) Post-Traumatic Ankle Arthritis. Bulletin of the Hospital for Joint Disease; 71(1): 104-12 